\title{
Female song and vocal interactions with males in a neotropical wren
}

\author{
Michelle L. Hall ${ }^{1 *}$, Maria R. D. Rittenbach ${ }^{2}$ and Sandra L. Vehrencamp \\ ${ }^{1}$ School of BioSciences, University of Melbourne, Melbourne, VIC, Australia \\ 2 School of Medicine, University of Maryland, Baltimore, MD, USA \\ ${ }^{3}$ Department of Neurobiology and Behavior, Cornell University, Ithaca, NY, USA
}

Edited by:

Geoffrey E. Hill, Auburn University, USA

\section{Reviewed by:}

Lyndon Alexander Jordan, The

University of Texas at Austin, USA

David Michael Logue, University of

Puerto Rico, USA

\section{${ }^{*}$ Correspondence:}

Michelle L. Hall, School of

BioSciences, University of

Melbourne, Building 147,

Melbourne, VIC 3010, Australia

e-mail: hall.m@unimelb.edu.au
Bird song is thought to function primarily in same-sex competition, mate attraction, and reproductive stimulation of a partner. However, these conclusions are based largely on studies of the song of male birds in north-temperate species. We investigate female song in a Neotropical wren, Thryophilus pleurostictus, using observations and experiments to test the function of female song. Female banded wrens sang much less often than males, their songs were shorter, and their repertoire of song types was smaller. Females did not seem to sing for same-sex competition for resources or mates: female song rate did not increase in response to simulated intrusion, and females sang in response to less than one-third of playbacks simulating territorial intrusion by either unpaired or paired females. Territorial defense is important for both survival and reproduction in species that occupy all-purpose territories year-round, but female involvement in territorial defense was limited. Females were more likely to approach simulated intruders when their partner approached more closely, and were closer to their partner during playback simulating a pair of intruders, perhaps contributing to defense jointly with their partner. Females did not appear to use song to attract males for mating: only $25 \%$ of females sang in response to playback simulating an unpaired male during the nest-building period, and they were less likely to sing shortly before laying when they were more likely to be fertile. Female song in banded wrens seemed to be used primarily for communicating with their breeding partner: female songs overlapped or began within $1 \mathrm{~s}$ of a song by their partner more often than expected by chance, and male vocal behavior changed in response to song by their partner. However, the low rate of female song in banded wrens suggests this function does not select for song elaboration, consistent with the view that same-sex competition is the main driver of female song elaboration.

Keywords: female song, female competition, mate attraction, duet, playback experiment

\section{INTRODUCTION}

Vocal and visual ornamentation of females was traditionally considered rare, with Darwin (1871) proposing that sexual dimorphism in ornamentation was due to sexual selection acting on males, and that examples of female ornamentation were due to shared inheritance of male characteristics. However, recent work on bird song has shown that song is widespread among female songbirds, and that female song was most likely present in the ancestor of modern songbirds (Odom et al., 2014). Thus, selection acting on females may be as, if not more, important than selection acting on males as a cause for sexually dimorphic bird song. Despite the prevalence of female song, much less is known about all aspects of female than male song (Riebel et al., 2005), including its function in inter- and intra-sexual competition and reproductive stimulation of a partner (primary functions of song in males, Catchpole and Slater, 2008). Since the theoretical framework for understanding the evolution of song was based largely on species where female song was rare, the role of vocal interactions with a breeding partner was generally not considered. However, most work on female song has been conducted in duetting species, where females often coordinate their songs with those of their partners to form joint acoustic displays (reviewed in Hall, 2004, 2009). Less is known about female song in species without conspicuous duets. Similarities and differences with male song, and the relative importance of female song for female-female competition, male attraction, and within-pair communication are all poorly understood.

Across taxa, females with visual or acoustic ornaments most commonly use them to compete for resources like territories and nest sites that are necessary for survival and reproduction (Tobias et al., 2012; Clutton-Brock and Huchard, 2013). Competition for resources is often sex-specific (females compete primarily with other females), but a comparative analysis of birds has shown that the same-sex bias in territorial defense behavior is considerably reduced in duetting species compared to non-duetting species (Logue, 2005). It is likely to be costly for females in sizedimorphic species to defend resources against males, but these costs of defense could be reduced if females engage in competitive 
behaviors jointly with a partner or group (for example, female lions, Panthera leo, roar in chorus to defend territories that are essential to reproduction and survival, McComb et al., 1994; Mosser and Packer, 2009). Thus, females may defend resources against females only or against both males and females (or, in principle, against males only). Furthermore, females may defend resources independently, or jointly with a partner.

Females in a range of taxa sometimes use ornamental traits to compete with other females for mates or to attract mates (Tobias et al., 2012; Clutton-Brock and Huchard, 2013). There are a few examples of female song functioning to attract males or compete with other females for males. Female song attracts males in alpine accentors Prunella collaris (Langmore et al., 1996). Female dunnocks Prunella modularis in multi-female groups are more likely to sing complex songs (Langmore and Davies, 1997). Females in this species compete for male parental investment and females in multi-female groups have reduced reproductive success (Davies, 1986), but we do not know how reproductive success of females in multi-female groups compares for those that sing vs. those that do not sing. Female eastern whipbirds Psophodes olivaceus sing highly synchronized answers to male song that form duets and function to defend their mated position against rival females in a system where offspring survival depends on exclusive access to male care and there is a female-biased sex ratio among unmated birds (Rogers and Mulder, 2004; Rogers et al., 2007).

Female song may also function in communication with a breeding partner to maintain group cohesion or to coordinate or stimulate breeding activity (Langmore, 1998; Hall, 2004, 2009). Species occupying dense habitat may need to maintain contact acoustically if visual contact is not possible (Thorpe, 1963; Mays et al., 2006). Biparental care is common in birds (Cockburn, 2006), and the ability of the sexes to coordinate and cooperate in the provision of care is likely to influence reproductive success (Halkin, 1997; Elie et al., 2010; Mariette and Griffith, 2012). Since calls are also suited to maintaining contact, such functions may not select for complex songs. Although greater complexity in male song is more effective at stimulating nest-building in females (Kroodsma, 1976), it is not known whether female song has a similar effect on males.

In species where both sexes sing, female songs may occur in close temporal association with those of their partner by chance, or they may be coordinated strategically to form duets. Song coordination is obviously strategic when the timing or types of male and female phrases within their synchronized songs are highly coordinated (for example, Mann et al., 2003; Hall, 2006; Logue, 2006). However, when entire songs of males and females occur close together in time without any temporal coordination of phrases within the songs (for example, Mennill and Vehrencamp, 2005; Hall and Peters, 2008), formal testing is necessary to distinguish duetting from chance temporal association. Song-type matching (or duet codes) and song overlapping (or alternating) provide evidence of strategic vocal interactions between partners rather than chance associations between their songs (Logue, 2007b), in much the same way that matching song-types and overlapping or alternating songs indicate when males are directing signals at a particular counter-singing male in a network (Searcy and Beecher, 2009).
The banded wren (Thryophilus pleurostictus) is a Neotropical wren in which both sexes sing (Molles and Vehrencamp, 1999). Female song is rare, and the species does not perform the highly coordinated antiphonal duets that characterize some related species (Molles and Vehrencamp, 1999; Mann et al., 2009). However, females sometimes participate in boundary disputes with their mates (Molles and Vehrencamp, 1999) and respond to playback of male song (Hall et al., 2006). Response to playback of female song has never been tested in this species, but male-male counter-singing interactions have been characterized in detail, based on observations and experiments (Molles and Vehrencamp, 2001; Burt and Vehrencamp, 2005; Hall et al., 2006; Illes et al., 2006; Vehrencamp et al., 2007, 2014; De Kort et al., 2009), as have male-female duets in many closely related species (Levin, 1996; Logue and Gammon, 2004; Gill et al., 2005; Marshall-Ball et al., 2006; Mennill and Vehrencamp, 2008). The singing style of banded wrens is similar to their congeners, rufous-and-white wrens (Thryothorus rufalbus) and sinaloa wrens (Thryothorus sinaloa), where rare female songs are occasionally loosely associated with the songs of their partner (Mann et al., 2009). Rufous-and-white wren duets are used in both within- and extra-pair communication, allowing partners to locate one another in their dense habitat and to jointly defend their territory (Mennill and Vehrencamp, 2008). However, the function of female song in banded wrens is unknown, and both the contexts in which females sing and the nature and significance of any vocal interactions between partners are unclear.

We combined observations and experiments to describe and investigate the function of female song and male-female vocal interactions in free-living banded wrens during the breeding season. We used songs recorded during early morning focal observations on pairs of banded wrens to describe the timing and type of female songs and male-female vocal interactions, as well as to test whether male and female songs were associated more often than expected by chance, or varied with context. We used playback experiments conducted during nest-building to test the effect of simulated intrusion on female song and male-female vocal interactions at a time when sexual conflict was likely to be at its peak. We compared responses to "paired intruders" (male and female song played as "duets") and to "solitary intruders" (male and female song played in separate trials). We tested predictions of key hypotheses for the function of female song and answering song that forms duets (summarized in Table 1):

(i) Intra-sexual territorial defense (female song) - Females approach and sing more when there is a female intruder (duet and female solo playback) than when no female intrudes (male solo playback). Female songs may overlap those of their partner by chance.

(ii) Joint territorial defense - Females approach and sing to all intruders, and respond more when there are more intruders (duet playback). Females are more likely to coordinate their response with their partner during duet playback (greater proximity and song answering).

(iii) Mate attraction (female song) - Females sing most when they are fertile if attracting males for extra-pair mating. If 
Table 1 | Predictions of hypotheses for the function of female song and answering song.

\begin{tabular}{|c|c|c|c|c|c|c|}
\hline & Nest-building & Partner distant & Solo Female PB & Solo Male PB & Duet PB & Sex-bias in Solo vs. Duet \\
\hline (i) Intra-sexual territorial defense & & & $\uparrow$ & & $\uparrow$ & $\mathrm{F} \uparrow / F \uparrow$ \\
\hline (ii) Joint territorial defense & & & $\uparrow$ & $\uparrow$ & $\uparrow(\mathrm{a} \uparrow)$ & $=1=$ \\
\hline (iv) Coordinate breeding & $\uparrow$ & & & & & \\
\hline (v) Locate partner & & $\uparrow$ & & & & \\
\hline
\end{tabular}

Contexts in which female song or answering song (a) (song given in response to partner's song to form a duet) are predicted to be most common under different hypotheses. Sex-biased responses to intruders can reflect closer approach to male than female playback (M), or closer approach to female than male playback (F), when male and female playback are presented separately (Solo) or simultaneously (Duet).

attracting a potential partner, females approach and sing most to an unpaired male (during male solo playback).

(iv) Coordinate or stimulate breeding activity (female song and answering song) - Females sing, or answer their partner's songs, most at the start of the breeding cycle (early nestbuilding).

(v) Locate partner (female song and answering song) - Females sing, or answer their partner's songs, from a distance.

\section{MATERIALS AND METHODS STUDY POPULATION AND APPROACH}

We studied a color-banded population of banded wrens at Santa Rosa National Park in the Guanacaste Conservation Area in Costa Rica $\left(10.83^{\circ} \mathrm{N}, 85.61^{\circ} \mathrm{W}\right)$ that has been the subject of a longterm research project (for details see Molles and Vehrencamp, 1999; Hall et al., 2009). The species is resident year-round and the sexes are somewhat size-dimorphic (mean mass for 86 females $=$ $18.3 \mathrm{~g}$, for 90 males $=20.3 \mathrm{~g}$ ). Both sexes contribute to parental care: nest-building is primarily (but not exclusively) by males, incubation is exclusively by females, and both sexes provision offspring.

To quantify (i) female song structure, repertoires and sharing, (ii) contexts of female song, and (iii) male-female vocal interactions, we recorded pairs singing naturally during and following the dawn chorus (approximately 5-7 a.m.). We recorded 12 pairs between 28 April and 2 August 2005 for a total of between 3.0 and $8.8 \mathrm{~h}$ each $($ mean $=6.0 \mathrm{~h})$, on $2-6$ days $($ mean $=3.8$ days $)$ at different stages of the breeding cycle. Observers attempted to estimate the distance between the male and female whenever a female song was heard.

To further test the function of female song and vocal interactions between partners, we conducted playback experiments to 16 pairs early in the breeding season, from 7 May to 10 June 2005. The playback stimuli comprised (i) female solo songs, (ii) male solo songs, and (iii) "duets" formed by playing male and female song stimuli simultaneously from two speakers. The "duet" treatment thus comprised loosely coordinated male and female songs (temporal coordination described in more detail below) with no precise coordination of phrases within songs, as is typical of the structure of duets in this species (see Results).

\section{FEMALE SONG STRUCTURE, REPERTOIRES, AND SHARING}

We recorded songs using a Sennheiser ME67 directional microphone and Marantz PMD 690 digital solid-state recorder, and used the program Syrinx-PC (www.syrinxpc.com-developed by John Burt, University ofWashington, Seattle) to visualize songs and measure song length. We tested for sex differences in song length by comparing means for males and females within 12 pairs, based on all of their songs. Most female songs were classifiable into types similarly to male song types in this species (Molles, 1999; Trillo and Vehrencamp, 2005). We generated plots of cumulative repertoire size vs. number of songs recorded for each of the 12 females to assess whether we could estimate their repertoire sizes reasonably accurately: only five females with 50 or more songs recorded appeared to reach an asymptote. We computed the standard song-type sharing index among the females $\left(I_{f}=2\right.$ $N_{s} /\left(R_{1}+R_{2}\right)$, where $N_{s}$ is the number of shared types between two females and the denominator is the sum of their total repertoire sizes) (McGregor and Krebs, 1982). The equivalent index $\left(I_{m}\right)$ was computed among the 12 males for comparison to the females. Because female repertoires were much smaller than male repertoires, we computed the sharing between a female and her mate as the fraction of her song types that were also present in her mate's repertoire. We computed this same shared fraction of song types between each female and the other 11 study males so that we could statistically evaluate whether or not females shared more songs with their mates than they do with other males.

\section{CONTEXTS OF FEMALE SONG}

We quantified male and female song rates (total songs sung per hour) in relation to stage of the breeding cycle (nest-building, laying, incubating, and provisioning nestlings or fledglings) and early or later in the morning (before vs. after 6 a.m.). Early morning periods began with the start of the male's first song, which ranged from approximately 4.55 to 5.20 a.m., and later morning periods terminated with the end of the last recorded male song, which ranged from approximately 6.20 to 7.15 a.m. We computed male and female song rates during early and late parts of each recording session, and used mixed models to test for differences in song rate associated with breeding stage and time of day, including pair ID as a random effect to control for the non-independence of multiple song rate estimates for each pair.

\section{COORDINATION WITH PARTNER}

To quantify vocal interactions and test whether female songs were closely associated with male songs by chance, simply because of the high song rates of males, we examined frequency histograms of response intervals and used a duty cycle approach (Ficken et al., 
1974; Maynard et al., 2012). We calculated female response intervals for each female song not preceded by another female song as the time between the beginning of the female song and the end of the partner's previous song; negative values indicate that the female song overlapped the male song. Individuals most commonly overlapped or began singing within $1 \mathrm{~s}$ of the partner's songs (see Results), consistent with the definition of duetting used for a sister-species, T. rufalbus (Mennill and Vehrencamp, 2005). To evaluate whether "duetting" by female banded wrens was random or occurred more or less often than expected by chance, we computed the proportion of female songs per recording session that overlapped or began within $1 \mathrm{~s}$ of a song by their partner (observed duetting rate). We then compared this with the proportion of female songs expected to form duet responses by chance, given the amount of time her partner was singing $=$ (sum of male song durations +1 s per male song)/recording duration. We computed similar observed and expected proportions of male songs that were sung either overlapping or beginning within $1 \mathrm{~s}$ of a female song.

Females sang intermittently in bouts of 1 to 39 songs that were often interspersed with male songs. We investigated vocal interactions between partners during bouts of concurrent song where the female sang at least three songs $(N=67)$. We noted whether the female's song type matched any of the 10 previous songs of her partner; matches included whole song type matches, trill matches, and introduction matches. Similarly, we noted whether the male's song matched any of the previous 10 songs of his partner, and whether he switched song types once the female started to sing to repertoire-match any of her song types. Observers had estimated the distance between the male and female for 59 of these bouts of concurrent song. To assess the changes in male singing behavior when the female interjects her songs, we compared the male's song rate, song duration, and fraction of songs shared with the mate during the interaction bout relative to the $5 \mathrm{~min}$ before the interaction bout.

\section{STEREO PLAYBACK EXPERIMENT}

We conducted playback experiments using a repeated measures experimental design to test the effect on responses of females and males to three treatments: (i) FS = female solo songs, (ii) $\mathrm{MS}=$ male solo songs, and (iii) $\mathrm{D}=$ "stereo duets" formed by playing male and female song sequences simultaneously from two speakers (see below for details on fine-scale timing). We presented the three treatments to each pair in three trials separated by intervals of 1 to 3 days. Due to the small sample size, rather than randomizing treatment order, we balanced the order of presentation so that half the pairs received the "duet" treatment first while the other half received it last, and female solos were presented before male solos to half the pairs and after male solos to the other half. Thus, four pairs each received one of the four sequences: D-FS-MS, DMS-FS, FS-MS-D, MS-FS-D; we did not use the remaining two possible treatment orders where the duet was between solos to avoid the possibility that subjects might "expect" a second bird in the final trial). We conducted the experiments on average $4.9 \pm$ 0.68 days before the female laid her first egg (range 16 to 2 days for 14 pairs with known laying dates), when the potential for sexual conflict over paternity would be at its peak. Each pair received a single playback treatment per day to reduce order effects, but all three treatments were presented over a 3- to 6-day period to minimize within-pair variation in female fertility. Half the pairs received all treatments while they were in the same nesting stage, and in the remaining pairs treatments spanned two of the three nesting stages.

We created 16 different sets of playback stimuli taken from recordings of 14 different pairs, so that each subject pair heard songs of a local (no more than $1 \mathrm{~km}$ away), unfamiliar (at least two territories away) pair. Each set of stimuli included recordings of two female songs, and three male song types that were in the repertoire of the subject male. We used the cursor-delimited filter in Syrinx to filter out noise, and then used Adobe Audition to amplify the songs to the same peak amplitude $(-5 \mathrm{~dB}$ for males, $-10 \mathrm{~dB}$ for females; relative amplitudes based on those in a recording of a male and female singing within $1 \mathrm{~m}$ of one another). To create the stereo stimulus files, female songs were pasted into the left channel and male songs into the right channel, in both cases switching between types until there were eight songs in each channel, spaced over $90 \mathrm{~s}$. The relative timing of male and female songs was arranged to give a mixture of female overlapping male $(\mathrm{M} / \mathrm{F})$, female following male $(\mathrm{MF})$ and vice versa within each stimulus to eliminate initiating sex and degree of temporal coordination as factors driving response. Duet stimuli were further balanced, with half starting off "female-initiated:" $\mathrm{F} / \mathrm{M} \mathrm{F} / \mathrm{M} \mathrm{M} / \mathrm{F} \mathrm{M} / \mathrm{F}$ FM MF M/F F/M, and the remainder starting off "male-initiated:" M/F M/F F/M F/M MF FM F/M M/F. The male solo stimulus was created from the duet stimulus by deleting female songs from the left channel, and the female solo stimulus was created by deleting male songs from the right channel. The solo stimuli for each sex were thus identical to the contribution of each sex to the "duet" stimuli.

Playback stimuli were presented using a two-speaker set-up for all trials (only one speaker broadcast songs during solo trials). The two speakers were placed $15 \mathrm{~m}$ apart and within the territory boundaries of the focal pair. Speakers were clearly marked "1" and "2" to be visible to observers from a distance. Channel was assigned to speaker by coin toss on the first trial to a pair, and kept consistent for the pair's remaining trials. We used flagging tape to mark the mid-point between the two speakers, as well as a radius of $15 \mathrm{~m}$ around each speaker (two points along the midline between the two speakers, and three on the outer part of the circumference of each speaker). These points were used as references for estimating subject location in the playback arena. Speaker positions were kept consistent in trials for each pair, with male songs played from one speaker and female songs from the other.

To calculate responses to playback, we quantified vocal and approach behavior of male and female subjects during each stage of the trials: 5-min observation period before playback (PRE), 90-s playback period when eight songs were broadcast at approximately $10 \mathrm{~s}$ intervals (PB), and 5-min observation period following playback (POST). Throughout the 11.5-min trial, one observer recorded all vocalizations produced by male and female subjects using a Marantz PMD690 with Sennheiser ME67 microphone. To estimate distances of male and female subjects to each of the two playback speakers, as well as to one another, two 
observers used Palm PDAs to plot the position of subjects onto a map of the playback arena on the PDA screen that showed the positions of the two speakers and the flagging tapes. From the audio records and PDA output, we computed the following response variables for both male and female subjects over the 6.5min PB+POST period: (i) song rate, (ii) the proportion of their songs that started within $1 \mathrm{~s}$ of the end of the partner's previous song, and (iii) their closest approach (m) to either speaker. We used the closest approach to either speaker rather than the active speaker(s) to avoid bias toward stereo duet treatments (any given location would be closer to an active speaker in trials with two active speakers than trials with one active speaker) and because of the possibility that birds might "remember" active speakers from earlier trials. (Differences between the two measures were small, and the number of females approaching within $15 \mathrm{~m}$ was identical whether either speaker or only the active speaker(s) was used.) We also computed an index of sex bias in speaker approaches to stereo playback, using $1-d_{s} /\left(d_{o}+d_{s}\right)$, where $d_{s}=$ closest distance to same sex speaker and $d_{o}=$ closest distance to opposite sex speaker (following Logue, 2005). Values greater than 0.5 indicate closer approach to the same-sex speaker, and values less than 0.5 indicate closer approach to the opposite-sex speaker.

We used a mixed modeling approach for analyzing responses to playback, controlling for the non-independence of trials to the same pair by including Pair ID as a random effect. Because females frequently did not sing or approach (see Results), we tested predictors of whether or not they (i) sang or (ii) approached in generalized linear mixed models with a binomial error distribution and a logit link. As fixed effects in the models, we included playback type (FS, MS, D), trial order (1-3), male song rate, male closest approach, time of day, day of year, and nesting stage. We targeted nest-building pairs, and when laying commenced we retrospectively determined nesting stage for the trials: Laying, Fertile $=$ up to 6 days prior to the start of laying, Pre-Fertile $=$ more than 6 days prior to laying. We tested predictors of male response using the same approach, except that we analyzed male song rate and the square-root transformation of male closest approach in linear mixed models because residuals were approximately normally distributed for these variables.

Statistical analyses were conducted using R 3.1.0 software ( $R$ Core Team, 2014). We report the means \pm SE for descriptive statistics throughout. For results of statistical models, we report effect sizes, $\beta \pm \mathrm{SE}$, associated with the tested explanatory variables. Our field methods were approved by Cornell University's animal care committee (protocol 98-81-07).

\section{RESULTS}

\section{FEMALE SONG STRUCTURE, REPERTOIRES, AND SHARING}

Female songs were shorter than male songs (mean duration $=$ $1.98 \pm 0.11$ vs. $3.04 \pm 0.06 \mathrm{~s}$; Wilcoxon signed rank test: $V=79$, $P<0.001, N=$ bird means for 12 pairs). A few female song types may be sex-specific, but most could be classified based on male song types, though they usually seemed softer, were more fragmentary (incomplete), and had less consistent trills than male songs (Figure 1).

Estimated female song repertoire sizes ranged from 9 to 13 song types (for five females with more than 50 songs recorded, when cumulative plots appeared to reach an asymptote). The average repertoire size of these five females was 10.4 song types, compared to the 20.4 song types that their male partners used (paired $t$-test: $\left.t_{4}=-5.59, P=0.005\right)$. Including all 12 females, female repertoire size estimates averaged 8.7 song types, and ranged as low as four song types (from a female that sang only 11 songs during $6.3 \mathrm{~h}$ of recording on four mornings).

Females shared more of their song types with their partner $(84.4 \%)$ than with other males $(67.8 \%$, on average, with the other 11 non-mate males; paired $t$-test: $\left.t_{11}=5.49, P<0.001\right)$ or nonmate males in their immediate neighborhoods (70.9\%; paired $t$-test: $\left.t_{10}=4.35, P=0.001\right)$. Song-type sharing was less common among females than among males: the female-female song sharing index $I_{f}$ was $34.8 \%$, compared to the male-male sharing index $I_{m}$ of $67.0 \%$ for their partners (paired $t$-test: $t_{10}=-7.38$, $P<0.001)$.

\section{CONTEXTS OF FEMALE SONG}

Females sang far less often than males during the breeding season: $4.9 \%$ of all songs recorded were by females. Song rates were much lower in females than males overall (songs/h $=8.4 \pm 1.8$ vs. $179.6 \pm 15.5$; Wilcoxon signed rank test: $V=0, P<0.001$, $N=$ bird means for 12 pairs), but varied with context. Female song rates were significantly lower during incubation and provisioning than during earlier stages of the nest cycle, and tended to decrease after the early morning (Figure 2A, Table 2A). Song rates differed among females (ID explained $24 \%$ of the total variance in song rate, and removing ID significantly worsened model fit: $\triangle \mathrm{AIC}=-6.3$, likelihood ratio $=8.32, P=0.004)$. In contrast, male song rates did not vary with breeding stage apart from an increase when the female was laying, but decreased dramatically after the early morning (Figure 2B, Table 2A). Song rates differed among males (ID explained $43 \%$ of the total variance in song rate, and removing ID significantly worsened model fit: $\Delta \mathrm{AIC}=-21.3$, likelihood ratio $=23.3, P<0.001)$.

\section{COORDINATION WITH PARTNER}

When females sang, partners' songs were often closely temporally associated (Figure 3). Female songs began within $30 \mathrm{~s}$ of a song by their partner $93 \%$ of the time, and closer associations were common. Both sexes were most likely to begin singing within $1 \mathrm{~s}$ of the end of their partner's song (modal response interval was 0 to $1 \mathrm{~s}$ ) or to overlap their partner's song (second-most frequent response interval was -1 to $0 \mathrm{~s}$, Figure 3 ). We thus used an operational definition of a "duet" response as an answering song that overlapped or began within $1 \mathrm{~s}$ of the end of a partner's song. Female song answers to form "duets" began $2.73 \pm 0.14 \mathrm{~s}$ after the start of their partner's song, while male song answers began $1.96 \pm 0.17 \mathrm{~s}$ after the start of their partner's song (Wilcoxon signed rank test: $V=72, P=0.007, N=$ bird means for 12 pairs). However, there was no sex difference in when answering songs started relative to the end of the partner's previous song (on average, females started singing $-0.31 \pm 0.14 \mathrm{~s}$, and males $-0.29 \pm 0.10 \mathrm{~s}$, from the end of their partner's song; Wilcoxon signed rank test: $V=35, P=$ $0.79, N=$ bird means for 12 pairs).

The large difference in song rates between males and females (above) meant that, on average, females gave an answering song 


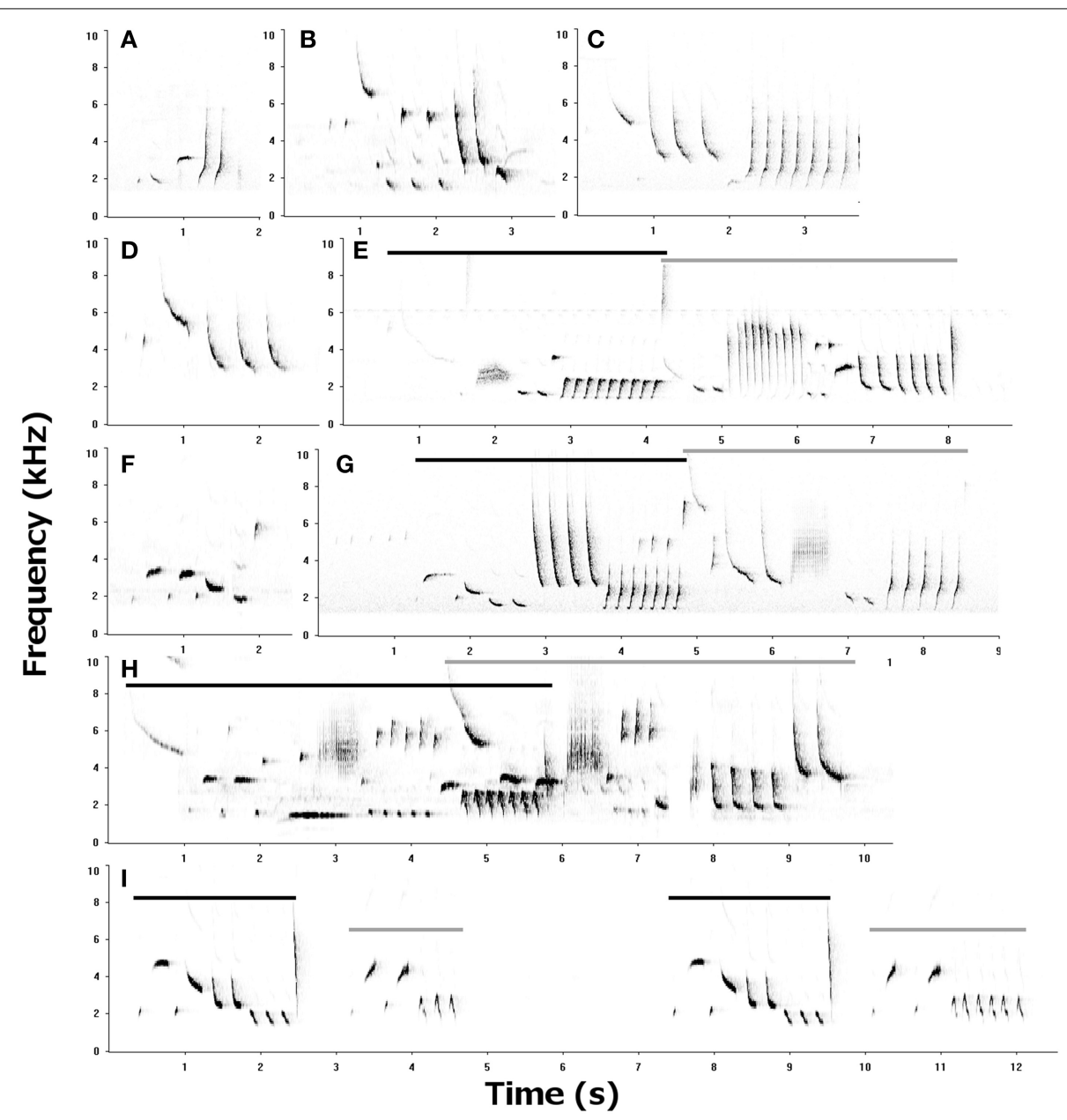

FIGURE 1 | Sonagrams of female songs (A-D, F) and male-female duets (E, G-I). Female song types are often similar to male song types, but more fragmentary. Songs given as answers to a partner's song vary from overlapping (as in $\mathbf{H}$ ) to closely following (as in $\mathbf{I}$ ). Light bars are used to identify female songs in duets, and dark bars identify male songs. Examples illustrate similarities between female and male song types, such as female song (C) and (F) with male song in (G). Fragmentary songs are shown in (A) and (D), while (B) and (E) show inconsistent trills. (H) shows a song type unique to females - the note types and general structure is similar to male song types, but there are no male song types that use the L-shaped note as a terminal trill. to only $1.9 \pm 0.4 \%$ of male songs, while males gave an answering song to $23.4 \pm 3.3 \%$ of female songs. However, the proportion of female songs that overlapped or began within $1 \mathrm{~s}$ of the end of a song by her partner $(0.38 \pm 0.03)$ was significantly higher than expected by chance [(sum of male song durations +1 s per male song)/recording duration $=0.20 \pm 0.02$; Wilcoxon signed rank test: $V=78, P<0.001, N=$ bird means for 12 pairs]. Similarly, the proportion of male songs that were answering songs $(0.011 \pm 0.002)$ was significantly higher than expected by chance based on the duty cycle of his partner $(0.007 \pm 0.001$; Wilcoxon signed rank test: $V=66, P=0.03, N=$ bird means for 12 pairs).

Although females and males answered their partners' songs to form duets more often than expected by chance, the likelihood of song answering (observed - expected proportion of songs that formed duets) did not vary with breeding stage or time of day, except that males were more likely to produce answering songs later in the morning (Figures 2C,D, Table 2B). Song answering also did not differ among females (ID explained 13\% of the total variance in female duetting, and removal of ID from the model did not change model fit: $\triangle \mathrm{AIC}=0.1$, likelihood ratio $=1.9$, $P=0.17)$. Similarly, song answering did not differ among males (ID explained $11 \%$ of the total variance in male duetting, and removal of ID from the model did not change model fit: $\triangle \mathrm{AIC}=$ 0.9 , likelihood ratio $=1.1, P=0.29$ ).

Male singing behavior changed during bouts of singing concurrently with their female $(N=67$ bouts with male song and at least three female songs, recorded from 10 pairs). During bouts when females were singing, males sang shorter songs than they had during the previous $5 \mathrm{~min}$ and a higher percentage of their songs were song types that they shared with their partner, but their song rate did not change (Table 3). On average, partners were estimated to be approximately $10 \pm 1 \mathrm{~m}$ apart (range: $1-40 \mathrm{~m}$ ) during bouts of concurrent song, and approached one other during $83 \%$ of bouts $(N=59$ with information on approach). 


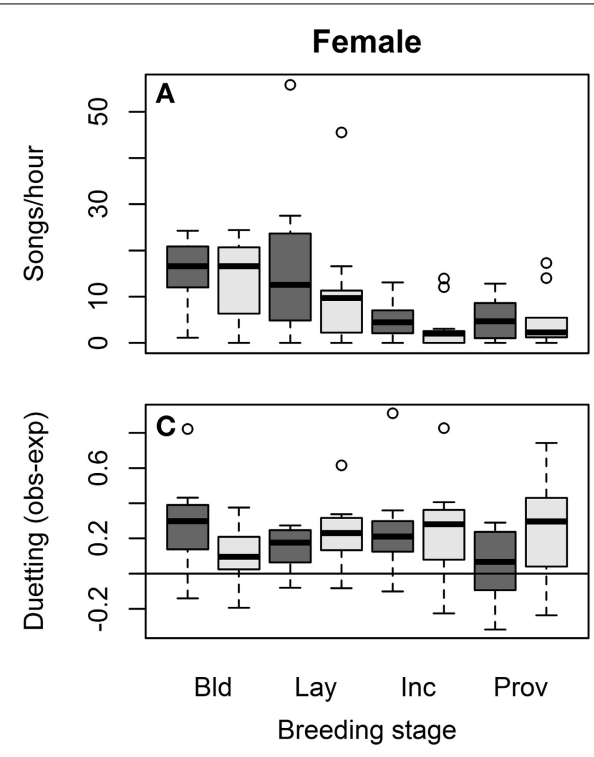

FIGURE 2 | Breeding stage and diurnal variation in female and male song. Variation in song rate associated with different stages of the breeding cycle (nest-building, egg-laying, incubation, and provisioning of nestlings or fledglings) and time of day (dark bars = before 6 a.m., light bars = after 6 a.m.) in (A) females and (B) males - note the 10-fold difference in scale of the $y$-axis between the sexes. Variation in the probability of answering song associated with different stages of the breeding cycle and time of day in (C)

Table 2 | Diurnal and breeding stage variation in song.

\begin{tabular}{ccc}
\hline & Female & Male \\
& $\boldsymbol{\beta} \pm \mathbf{S E}, \boldsymbol{P}$ & $\boldsymbol{\beta} \pm \mathbf{S E}, \boldsymbol{P}$ \\
\hline (A) SONG INITIATION RATE & \\
Breeding stage - laying & $-0.53 \pm 0.45,0.24$ & $1.58 \pm 0.80,0.05$ \\
- incubating & $\mathbf{- 1 . 7 2} \pm \mathbf{0 . 4 3 , < 0 . 0 0 1}$ & $1.18 \pm 0.77,0.13$ \\
- provisioning & $\mathbf{- 1 . 4 1} \pm \mathbf{0 . 5 0 , 0 . 0 0 6}$ & $1.46 \pm 0.90,0.11$ \\
Time - late & $-0.52 \pm 0.29,0.08$ & $\mathbf{- 2 . 5 2} \pm \mathbf{0 . 5 1 ,} \mathbf{0 . 0 0 1}$ \\
(B) SONG ANSWERING & & \\
Breeding stage - laying & $-0.04 \pm 0.08,0.63$ & $0.001 \pm 0.07,0.87$ \\
- incubating & $0.06 \pm 0.08,0.46$ & $-0.07 \pm 0.07,0.33$ \\
Time - late & $-0.05 \pm 0.09,0.54$ & $-0.07 \pm 0.08,0.38$ \\
\hline
\end{tabular}

Variation in (A) song rate (songs/min) and (B) song answering lobserved expected proportion of songs beginning within $1 \mathrm{~s}$ of the end of a partner's song) with breeding stage (effects relative to nest-building stage) and time of day (relative to early morning) in females and males. Statistically significant effects are in bold.

\section{STEREO PLAYBACK EXPERIMENT}

Females did not respond strongly to simulated territorial intrusion overall. Females sang during the pre-playback period in $23 \%$ of 48 trials and during the playback period in only $25 \%$ of trials, and their song rate did not change (songs/min $=0.07 \pm$ 0.02 before, $0.12 \pm 0.05$ playback; Wilcoxon signed-rank test $V=119, P=0.92$ ). Females that did not sing were also less likely to approach to within $15 \mathrm{~m}$ of the speakers $\chi^{2}=4.21, D F=$ $1, P=0.04)$. In contrast, males sang during the pre-playback
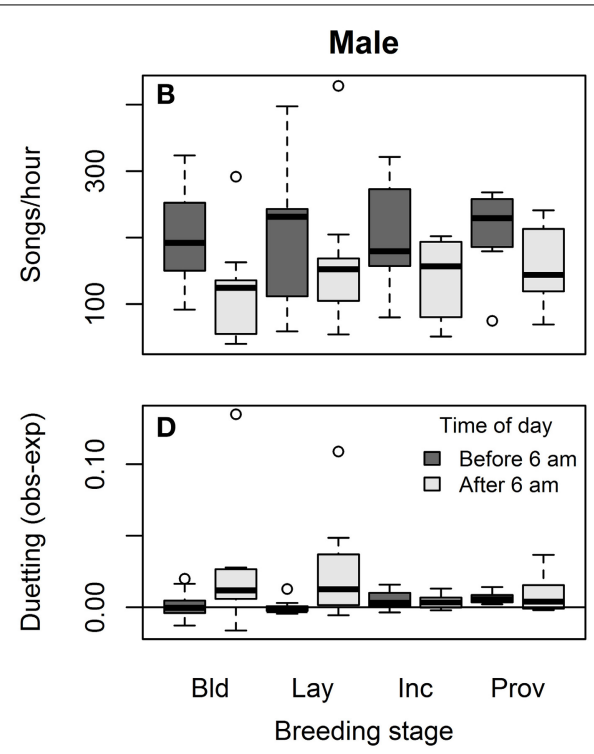

females and (D) males. The y-axis shows the difference between the observed and expected probability of answering song, where the observed probability of answering song is the proportion of the bird's songs that overlap or begin within $1 \mathrm{~s}$ of the end of its partners songs, and the expected probability of answering song depends on its partner's duty cycle: (sum of song durations plus $1 \mathrm{~s}$ per song)/session duration. Again, note the difference in scale of the $y$-axis between the sexes.

period in $83 \%$ of trials and during the playback period in $96 \%$ of trials, with higher song rates in response to playback (songs $/ \mathrm{min}=1.06 \pm 0.17$ before, $2.20 \pm 0.20$ playback; Wilcoxon signed-rank test $V=206, P<0.001)$. Song and approach were negatively correlated in males: males sang less in trials where they approached playback more closely (Spearman correlation $r=-0.43, P=0.002$ ).

Females were equally (un)likely to sing (Figure 4A) and to approach (Figure 4C) in response to the three playback treatments (Table 4). Females tended to be more likely to sing during "pre-fertile" trials (early in the nest-building period, at least 6 days before egg-laying) than during "fertile" trials (within 6 days of laying) (no other covariates affected female song, Table 4A). Females were less likely to approach when their partner did not approach as closely, and tended to be less likely to approach later trials than earlier trials (no other covariates affected female approach, Table 4B).

Males responded to the three playback treatments with similar song rates (Figure 4A) and closest approach (Figure 4D) (Table 4). Male song rate decreased with time of day (no other covariates affected male song, Table 4A). Males tended to approach more closely (closest approach distance was smaller) when their partner approached, and they approached more closely during first trials than later trials (no other covariates affected male song, Table 4B). However, the effect of trial order varied with playback type: close approaches to male and female solos dwindled with trial order (approach distance increased), whereas duets elicited equally close approaches whether they were presented first or last (Figure 5; order $\times$ playback interaction effect relative to Duet for: Male Solo $=1.31 \pm 0.49, P=0.01$, 


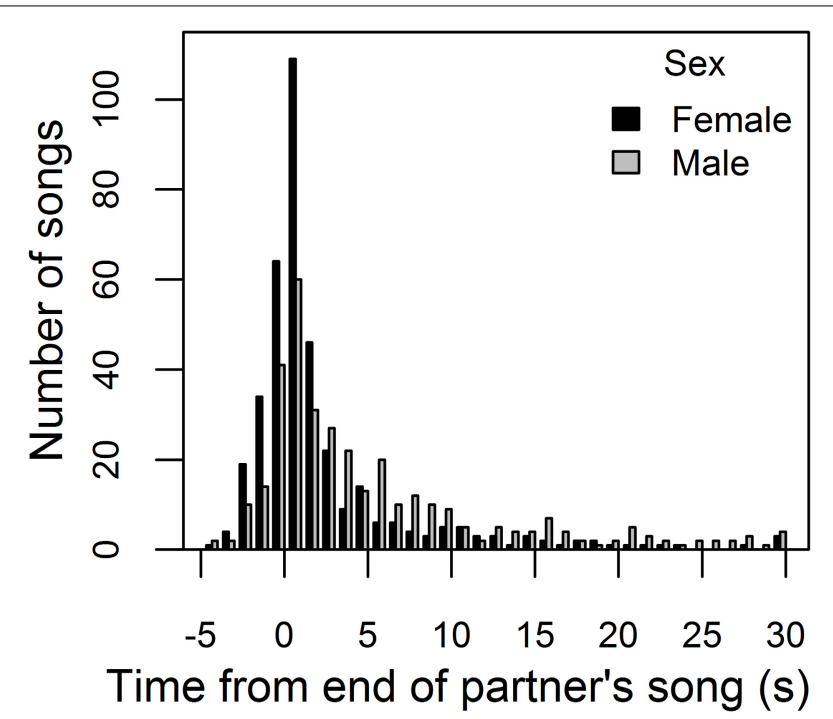

FIGURE 3 | Distribution of female and male response intervals.

Frequency histogram of response intervals: time between the start of a female (male) song and the end of the preceding male (female) song, shown in black (gray). Labels on the x-axis indicate upper bounds of 1-s bins. Intervals less than zero indicate that the female (male) overlapped their partner's song, commencing a song while their partner was singing. The plot excludes response intervals greater than $30 \mathrm{~s}$ (that represent $7 \%$ of female and $14 \%$ of male response intervals).

Table 3 | Male singing behavior before and during bouts of concurrent song with female.

\begin{tabular}{lllcc}
\hline & Before & During & $\begin{array}{c}\text { Wilcoxon } \\
\text { signed-rank }\end{array}$ & $\boldsymbol{P}$ \\
& & & 20 & 0.49 \\
\hline Song rate (songs/min) & $3.88 \pm 0.40$ & $4.07 \pm 0.43$ & 52 & 0.01 \\
Song duration (s) & $2.98 \pm 0.08$ & $2.66 \pm 0.10$ & 3 & 0.01 \\
Shared songs (\% songs) & $46.1 \pm 8.1$ & $60.9 \pm 7.6$ & &
\end{tabular}

Paired comparisons are based on per-male means of singing behavior in the 5min period before, and during, 67 bouts of concurrent song (male song bout when female sang at least three songs) recorded from 10 pairs. Means are presented with standard errors of means.

Female Solo $=0.98 \pm 0.50, P=0.06$, in mixed model controlling for whether or not the female approached).

Females tended to show less sex-specificity than males in approaching simulated intruders, and partners stayed closest to one another during duet playback. Females approached male and female playback equally closely overall (mean \pm SE sex-bias $=$ $0.51 \pm 0.06$ using a sex-bias score where 0.5 indicates no bias and 1 indicates response to same-sex only, from Logue, 2005), while males tended to show a stronger same-sex bias than their partners overall (mean \pm SE sex-bias score $=0.60 \pm 0.04$; sex effect on bias score $=0.20 \pm 0.11, P=0.07$; Figure 6A). The sex-specificity of approach responses did not differ depending on whether paired or solitary intruders were simulated (Duet vs. Solo playback effect on bias score $=0.15 \pm 0.15, P=0.31$ ). The interaction between sex and playback type suggested in Figure 6A was not statistically significant $(-0.26 \pm 0.17, P=0.13)$, possibly because of the low numbers of females that approached the speakers. The closest distance between partners was smaller during duet playback than during solo trials (Figure 6B, effect relative to Duet $=1.59 \pm$ 0.66, $P=0.05$ for Female Solo, $1.59 \pm 0.58, P=0.03$ for Male Solo, in mixed model controlling for an increase in closest distance between partners with day-of-year $=0.08 \pm 0.03, P=0.04$; no other covariates influenced the distance between partners).

In the trials when females sang $(N=12)$, on average $64 \%$ of their songs commenced within $1 \mathrm{~s}$ of the end of a song by their partner, a trend for a higher likelihood than the 38\% during unprompted singing above (Wilcoxon $\mathrm{W}=42, P=0.09$ ). Only 3 to 5 females sang per playback type (Figure 4B), and we did not detect any effect of playback type on the proportion of their songs given as answering songs to form duets (60\% to Duet, $50 \%$ to Female Solo, and 79\% to Male Solo; Kruskal-Wallis $\chi^{2}=0.83$, $D F=2, P=0.66)$.

\section{DISCUSSION}

Female banded wrens were much less vocal than males, and we found little evidence that they used song for intra-sexual competition for resources or mates, or to attract males. Instead, female song appeared to function primarily for within-pair communication. Females responded to simulated intrusion by singing or approaching in only around one third of trials, their song rate did not increase in response to playback, and their likelihood of response was similar to playback simulating paired male and female intruders, solitary female intruders, and solitary male intruders. Our findings in this species where females sing much less than males and invest little in resource defense are consistent with the view that intense resource competition among females selects for more elaborate female song.

\section{FEMALE SONG}

Banded wrens provide an example of a Neotropical species where female song is much less elaborate than male song, with considerably lower song rates, shorter songs, and smaller repertoire sizes. These sex differences parallel those found in the closely related T. rufalbus where female song output represented $7 \%$ of all songs (Mennill and Vehrencamp, 2005), vs. 5\% in banded wrens. Sex differences in repertoire sizes between the two species (10.0 vs. 20.4 song types in banded wrens and 8.5 vs. 10.8 in T. rufalbus) appear primarily due to the larger repertoire size of male banded wrens. In some species, female song is somewhat less frequent and less complex than male song, for example in pied bush chats Saxicola caprata (Sethi et al., 2012), superb fairy-wrens Malurus cyaneus (Kleindorfer et al., 2013) and European starlings Sturnus vulgaris (Pavlova et al., 2005). However, in other species females sing as much (Pilowsky and Rubenstein, 2013) or more (Price et al., 2008; Illes and Yunes-Jimenez, 2009) than males. The considerable variation in female song elaboration from no song (Garamszegi et al., 2007; Odom et al., 2014) to females that out-sing males suggests that female songbirds provide a powerful system for testing theories about factors that limit or promote the elaboration of bird song.

The complexity of bird song is thought to be a result of the songbird capacity for vocal learning, but little is known about vocal learning in females (Riebel, 2003; Riebel et al., 2005). 


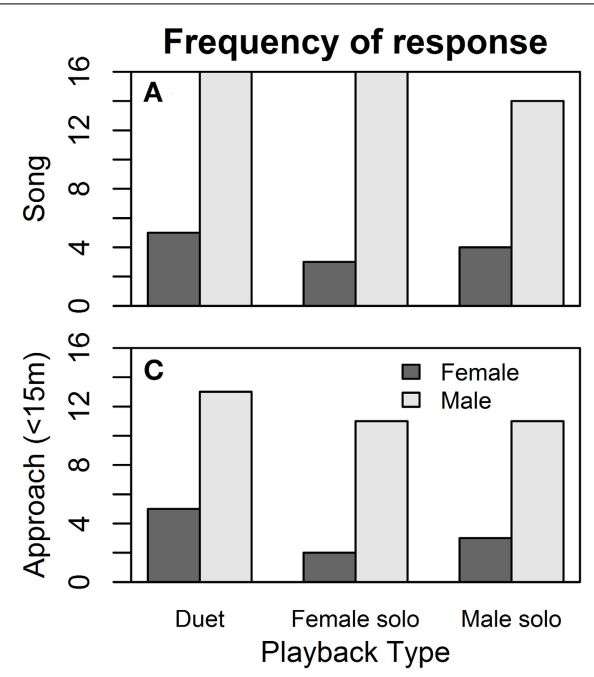

FIGURE 4 | Effect of playback on song and approach responses. Female (dark gray) and male (light gray) responses to duet-, female solo-, and male solo-playback in terms of the number of birds
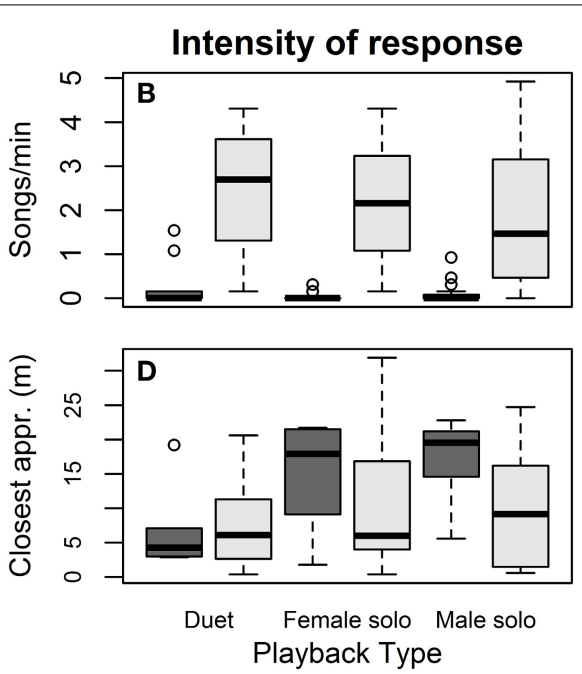

singing (A) and their song rates (B), and the number of birds approaching within $15 \mathrm{~m}$ of the speakers (C) and their closest approach distance (D)
Patterns of song type sharing raise intriguing questions about vocal learning in female banded wrens and other species. Shared song types were less common among females than among males in banded wrens (30 vs. $67 \%$ ), a pattern similar to that found in T. rufalbus (26 vs. 59\%, Mennill and Vehrencamp, 2005). The appearance of female banded wren song types as fragmentary versions of male song types might suggest female songs result from a genetic correlation with selection for vocal learning in males. However, some female song types are unique to females, implying that they must be learned from other females. Nevertheless, females share more of their repertoire with their male partner than with other females or other males, suggesting that some songs may be learned from males and that some learning, or selection of already-learned types, takes place after natal dispersal and pair formation (or that pairing is assortative). The sex differences in song sharing in banded wrens contrast with the plain wren Cantorchilus modestus, an antiphonal duetter with sexspecific song phrases, where sharing levels did not differ between the sexes, but did differ between populations ( 52 vs. $22 \%$ shared) (Marshall-Ball and Slater, 2008).

\section{INTRA-SEXUAL OR JOINT TERRITORIAL DEFENSE}

In species that occupy all-purpose territories year-round, territorial defense is critical to fitness because territories provide the resources necessary for both survival and reproduction. However, females did not increase their song rate in response to simulated intrusion, and they were much less likely than males to defend the territory against intruders. We found no evidence that females directed their song exclusively at female intruders: they were equally likely to sing in response to both male and female intruders. There was also no sex-bias in female approach response, regardless of whether "intruders" were paired (female and male songs played simultaneously in duet playback) or solitary (female and male songs played on different days in solo playbacks, Figure 6A). Females tended to sing more answering songs during playback than during undisturbed singing, and were more likely to approach simulated intrusion when their partner approached closely. During duet playback, partners were also significantly closer to one another than during solo playback (Figure 6B), consistent with the idea that females contribute to joint territorial defense with their partner when there is a greater threat - two intruders vs. one (or perhaps that they benefit from his protection, or reduce risk of mistaken attack by their partner, Logue and Gammon, 2004).

Treatment order effects on male approach behavior also suggested duet playback may have posed a greater threat, since it attracted close approaches by males whether presented first or last in the sequence, whereas solo playback attracted close approaches only when presented first in the sequence (see decay in intensity of approach response with prior exposure to playback in Figure 5). Previous work has shown order effects in both female and male banded wrens (Hall et al., 2006; Kovach et al., 2014), and we deliberately used a factorial experimental design for treatment order, rather than fully randomizing, so that balanced presentation orders would minimize bias on treatment effects and provide statistical power for testing order effects. Other studies have also found effects of prior experience with playback on behavior (Naguib, 1999; Amrhein and Erne, 2006), suggesting that this is an important consideration in the design of experiments and when using playback to attract birds for capture prior to conducting experiments.

Our findings contrast with other studies suggesting that intrasexual aggression for resource defense is the primary function of female song, but are consistent with the idea that high female song rates and/or complexity are associated with resource defense. A cross-taxonomic review identified female competition for resources such as territories and nest sites as a primary function of elaborate signal traits in females (Tobias et al., 2012). In birds, female European starlings sing primarily to defend nest-boxes (Pavlova et al., 2007). Female European robins Erithacus rubecula 
Table 4 | Effect of playback treatments on song and approach by females and males.

\begin{tabular}{|c|c|c|}
\hline & $\begin{array}{c}\text { Female (yes/no) } \\
\qquad \beta \pm \mathrm{SE}, P\end{array}$ & $\begin{array}{l}\text { Male (songs/min) } \\
\quad \beta \pm \mathrm{SE}, P\end{array}$ \\
\hline \multicolumn{3}{|l|}{ (A) SONG } \\
\hline \multicolumn{3}{|l|}{ Fixed Effects } \\
\hline Treatment - Female solo & $-0.59 \pm 0.92,0.52$ & $-0.32 \pm 0.32,0.47$ \\
\hline - Male solo & $-0.41 \pm 0.84,0.63$ & $-0.70 \pm 0.43,0.12$ \\
\hline Order & $-0.48 \pm 0.51,0.34$ & $0.15 \pm 0.22,0.49$ \\
\hline Nest stage - Pre-fertile & $1.50 \pm 0.79,0.06$ & $-0.07 \pm 0.46,0.88$ \\
\hline - Laying & $1.04 \pm 1.11,0.35$ & $-0.22 \pm 0.64,0.73$ \\
\hline Own song pre-playback & $-0.55 \pm 0.93,0.56$ & $0.20 \pm 0.16,0.23$ \\
\hline Partner song & $-0.23 \pm 0.27,0.38$ & $-0.29 \pm 0.43,0.51$ \\
\hline Partner approach & $-0.01 \pm 0.04,0.85$ & $0.18 \pm 0.48,0.71$ \\
\hline Time of day & $0.26 \pm 0.47,0.60$ & $-0.59 \pm 0.25,0.03$ \\
\hline Day of year & $-0.02 \pm 0.04,0.69$ & $0.00 \pm 0.03,0.99$ \\
\hline Random Effect & $\sigma$ & $\sigma$ \\
\hline Pair ID & 0.00 & 0.24 \\
\hline \multicolumn{3}{|l|}{ (B) APPROACH } \\
\hline \multicolumn{3}{|l|}{ Fixed Effects } \\
\hline Treatment - Female solo & $-1.97 \pm 1.38,0.16$ & $0.24 \pm 0.34,0.48$ \\
\hline - Male solo & $-1.99 \pm 1.55,0.20$ & $0.15 \pm 0.33,0.65$ \\
\hline Order & $-1.45 \pm 0.79,0.06$ & $0.45 \pm 0.18,0.02$ \\
\hline Nest stage - Pre-fertile & $1.42 \pm 1.28,0.27$ & $0.45 \pm 0.46,0.33$ \\
\hline - Laying & $2.51 \pm 2.68,0.35$ & $0.68 \pm 0.57,0.24$ \\
\hline Partner song & $-0.28 \pm 0.36,0.43$ & $0.18 \pm 0.37,0.63$ \\
\hline Partner approach & $-2.01 \pm 0.98,0.04$ & $-0.77 \pm 0.43,0.08$ \\
\hline Time of day & $0.35 \pm 0.73,0.63$ & $0.07 \pm 0.28,0.81$ \\
\hline Day of year & $-0.04 \pm 0.07,0.57$ & $0.02 \pm 0.03,0.46$ \\
\hline Random Effect & $\sigma$ & $\sigma$ \\
\hline Pair ID & 0.37 & 0.61 \\
\hline
\end{tabular}

Results of mixed models assessing factors affecting female and male response to playback, including Pair ID as a random effect to control for the nonindependence of trials on the same pair. Female responses (sang or not, and approached within $15 \mathrm{~m}$ of speakers or not) were modeled in binomial generalized linear mixed models (GLMMs) with a logit link, and male responses (songs/min, and square-root transformed closest approach distance in meters) were modeled with linear mixed models (LMMS). Effects ( $\beta \pm S E$ ) of categorical factors are reported relative to a reference level (Duet playback for the Treatment effect, and Fertile for the Nest stage effect). Effects of variables with non-significant effects on response are reported from separate models that controlled only for Playback Treatment and other variables with $P<0.1$ (in bold). (Full models including all fixed effects simultaneously gave qualitatively the same results, but sometimes failed to converge.)

sing in winter, when they maintain territories separately from males (Hoelzel, 1986; Schwabl, 1992), and female song in superb fairy-wrens is used to defend territories in a species where males are often absent from the territory (Cooney and Cockburn, 1995). Female song in these species is less elaborate than male song (Pavlova et al., 2005; Kleindorfer et al., 2013), but sex differences are not dramatic, for example in superb fairy-wrens around $45-50 \%$ of females and $50-65 \%$ of males sang in response to playback of neighbor songs (from Figure 3, Cooney and Cockburn, 1995). In contrast, the strong sexual dimorphism in song output in banded wrens during the breeding season, where females sang

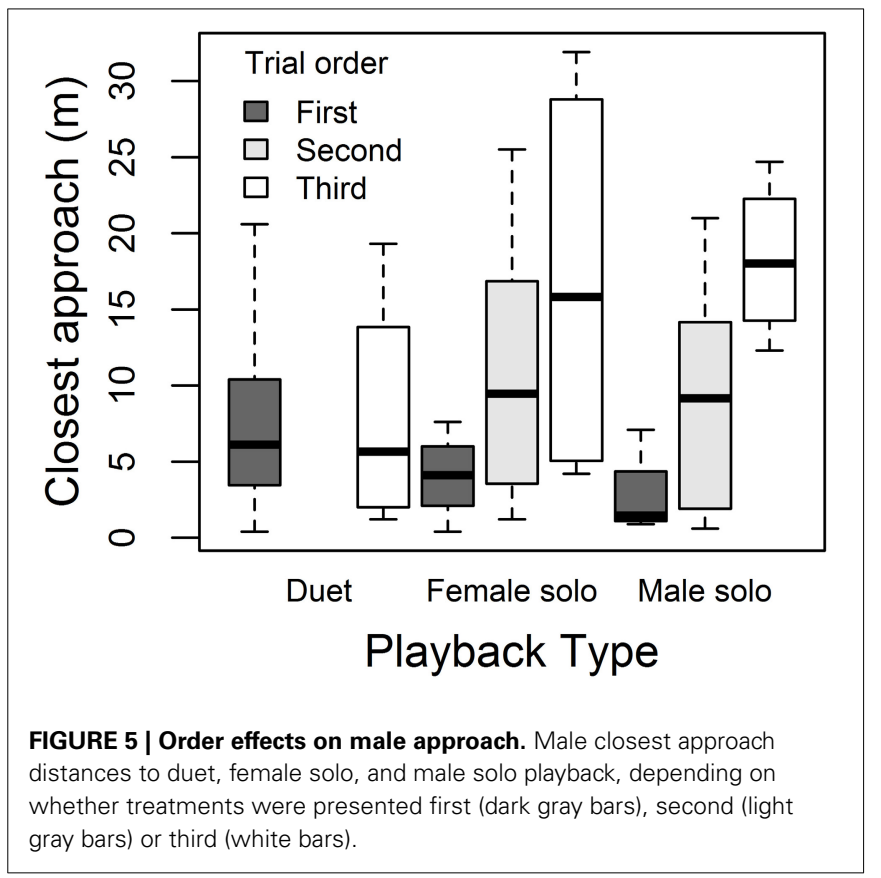

only around 5\% of songs, was associated with reduced involvement in territorial defense and a lack of female-specific aggression in territorial defense. Further work is needed to determine whether female song differs during the non-breeding (tropical dry) season, when they are not investing in reproduction and resources are less abundant.

\section{COMPETITION FOR MATES OR MATE ATTRACTION}

We found little evidence that female banded wrens sing to advertise their fertility and attract extra-pair males, even though they occasionally mate with males other than their partner ( $4 \%$ of offspring in $10 \%$ of nests are a result of extra-pair mating, Cramer et al., 2011). Although natural female song rates were high during nest-building as predicted, during simulated intrusion in the nest-building period, females sang less in the 6 days immediately prior to egg-laying (when they were most likely to be fertile) than earlier in nest-building, and did not sing more to simulated solitary male intruders than to other playback treatments (Figure 4A). High female song rates early in nest-building could attract extra-pair males for extra-pair mating later in the cycle, but the number of females with extra-pair offspring was too low to test this idea.

High female song rates during early nest-building are consistent with a role in stimulating and synchronizing reproductive activity with a breeding partner. Although the start of nesting is synchronized with the start of the rainy season, breeding and renesting continues for four or five months with fewer external cues for synchronizing partners (Cramer et al., 2011). Furthermore, although females perform all incubation in this species, male banded wrens do the majority of nest-building. Future observational and experimental work targeting the early part of the nesting cycle would be useful to test whether female song in banded wrens stimulates nest-building activity by their male partners, in the same way that male song has been shown to 


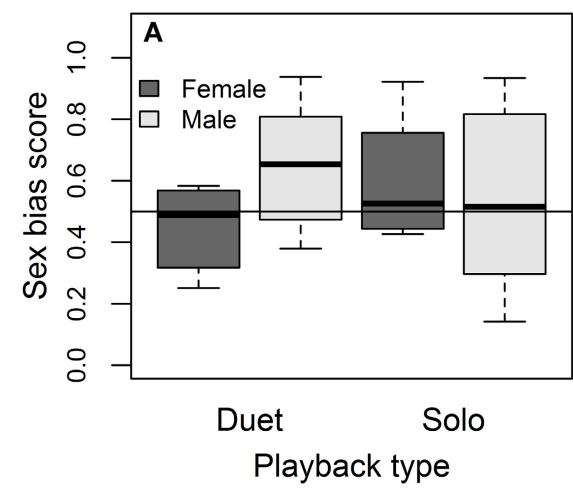

FIGURE 6 | Sex-specificity and coordination of approach to playback. (A) Sex bias in female and male approach during duet playback (male and female songs played simultaneously, simulating pair intrusion) and during solo playback (when male and female songs played on different days, simulating intrusion by solitary birds). The line at 0.5 indicates equally close approaches to same- and opposite-sex playback, while

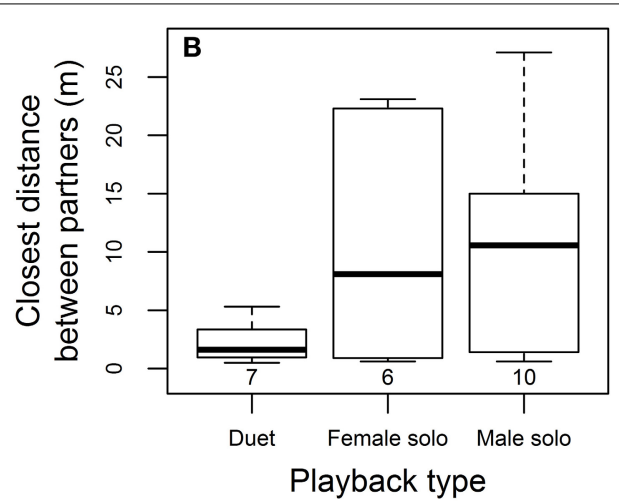

scores above the line indicate closer approaches to same-sex playback [sex bias $=1$ - closest approach to same-sex playback/(closest approach to same-sex playback + closest approach to opposite-sex playback), from Logue, 2005]. (B) Closest distance between partners during playback treatments, with the number of pairs for which data was available in each playback type indicated in parentheses. stimulate nest-building by females in other species (Kroodsma, 1976).

\section{COORDINATION WITH PARTNER}

Female songs were closely associated with male songs more frequently than expected by chance, and elicited changes in male singing behavior. Duetting species fall into two categories, those where individuals answer the whole song of their partner (song coordination), and those where individuals answer the song of their partner with coordination on a phrase-by-phrase basis within the song (song and phrase coordination) (Hall, 2009). Banded wrens fall into the first category, as individuals did not coordinate phrases in their own songs with their partner's phrases in the songs they overlapped (Figure 1H) in the way that many antiphonally duetting species do (Mann et al., 2003; Hall, 2006; Logue et al., 2008). Females sang on average 38\% of their songs as answers to male songs (overlapping or beginning within $1 \mathrm{~s}$ of the end of the male's song, Figure 3), which was almost twice the likelihood that a female song would form such a duet by chance $(20 \%)$. Males changed their singing style when their partner began singing, using a higher percentage of shared song types and singing songs with shorter durations during bouts of concurrent song than they had been previously. Males sang only $1.1 \%$ of their songs as answers to female songs, but this was also more frequent than expected by chance $(0.7 \%)$. Slower female than male duet responses to the start of their partner's previous song were also found in T. rufalbus (Mennill and Vehrencamp, 2005). In banded wrens, this delay seemed to be due to females anticipating and accommodating longer male song durations, since males and females both started their answering songs on average about $300 \mathrm{~ms}$ before the end of their partner's previous song to create a slight overlap. Work on neural mechanisms underlying temporal coordination of rapidly alternating phrases in duets by plain-tailed wrens (Pheugopedius euophrys) showed that pre-motor circuits encode contributions from both partners, not just their own (Fortune et al., 2011). However, duetting is not well-developed in banded wrens. Response intervals were quite variable, with no clear distinction between "duets" and "solos," as response intervals that were more frequent than baseline ranged up to 5 or $6 \mathrm{~s}$ long (Figure 3), which is two or three times the duration of an average song.

Banded wren partners were, on average, about $10 \mathrm{~m}$ apart during bouts of concurrent singing, distances that limit visual contact in their forest habitat during the wet season, suggesting the potential for song to allow partners to maintain contact with one another. In Steere's liocichla (Liocichla steerii), females living in dense forest habitat were more likely to answer male songs than females in open agricultural habitat (Mays et al., 2006). Future work on banded wrens could similarly contrast the frequency of answering song during the wet season with the dry season, when visibility is high in their deciduous forest habitat. More detailed work on other forest-dwelling Neotropical wrens using radiotracking (Logue, 2007a) and passive acoustic location of singing individuals (Mennill and Vehrencamp, 2008) has shown that duet responses are often given by individuals more than $10 \mathrm{~m}$ from their partner, with the initiator then moving closer to its partner, suggesting that duetting functions cooperatively in maintaining contact and pair cohesion. Banded wrens and other species that duet when partners are not perched next to one another thus contrast with duetting species that sing together while perched within a meter or two of one another (for examples, see Short and Horne, 1982; Hall and Magrath, 2000; Hall and Peters, 2008; Dowling and Webster, 2013).

\section{CONCLUSIONS}

Female banded wrens sang much less often than males, but nevertheless had a repertoire of song types. Their songs overlapped or closely followed the songs of their partner more frequently than expected by chance, to form occasional loose "duets." When females sang, their male partners changed their singing style to use more shared song types. Females responded to about one-third of simulated intrusions, but their song and approach were not directed solely at female intruders. Instead, females may contribute to territorial defense jointly with their partner, 
showing little sex-specificity in their response to intruders, approaching simulated intruders more closely when their partner approaches most closely, and being closer to their partner when "paired intruders" were present. Males did the majority of territorial defense, and infrequent female song in this species during the breeding season seems to be associated with low female investment in territorial defense. Female fecundity generally depends on access to resources (Trivers, 1972), but females may reduce investment in ornamental visual and vocal traits used in competitive interactions if their partner invests heavily in defending the resources that females use. The use of song primarily for communication with a breeding partner may not drive trait elaboration.

\section{ACKNOWLEDGMENTS}

We thank Anya Illes, Erin Bohman, and Jessica Niederer for assistance with field recordings and experiments. We also thank Roger Blanco and Maria Marta Chavarria and other staff at Santa Rosa National Park in The Área Conservación de Guanacaste, Costa Rica, for hosting and supporting our research there. This research was funded by the National Institute of Mental Health (Grant R01-MH60461), and adhered to the Animal Behavior Society Guidelines for the Use of Animals in Research, the legal requirements of Costa Rica, and all institutional guidelines. Song recordings illustrated in Figure 1 have been deposited in the online repository for sharing bird song http://www.xeno-canto. org. Other data are available from the authors on request.

\section{REFERENCES}

Amrhein, V., and Erne, N. (2006). Dawn singing reflects past territorial challenges in the winter wren. Anim. Behav. 71, 1075-1080. doi: 10.1016/j.anbehav.2005.07.023

Burt, J. M., and Vehrencamp, S. L. (2005). "Dawn chorus as an interactive communication network," in Animal Communication Networks, ed P. K. McGregor (Cambridge: Cambridge University Press), 320-343.

Catchpole, C. K., and Slater, P. J. B. (2008). Bird Song: Biological Themes and Variations. Cambridge: Cambridge University Press. doi: 10.1017/CBO9780511754791

Clutton-Brock, T. H., and Huchard, E. (2013). Social competition and selection in males and females. Philos. Trans. R. Soc. B Biol. Sci. 368:20130074. doi: 10.1098/rstb.2013.0074

Cockburn, A. (2006). Prevalence of different modes of parental care in birds. Proc. R. Soc. B Biol. Sci. 273, 1375-1383. doi: 10.1098/rspb.2005.3458

Cooney, R., and Cockburn, A. (1995). Territorial defence is the major function of female song in the superb fairy-wren, Malurus cyaneus. Anim. Behav. 49, 1635-1647. doi: 10.1016/0003-3472(95)90086-1

Cramer, E. R. A., Hall, M. L., De Kort, S. R., Lovette, I. J., and Vehrencamp, S. L. (2011). Infrequent extra-pair paternity in the banded wren, a synchronously breeding tropical passerine. Condor 113, 637-645. doi: $10.1525 /$ cond.2011.100233

Darwin, C. (1871). The Descent of Man, and Selection in Relation to Sex. London: John Murray. doi: 10.1037/12293-000

Davies, N. B. (1986). Reproductive success of dunnocks, Prunella modularis, in a variable mating system. I. Factors influencing provisioning rate, nestling weight and fledging success. J. Anim. Ecol. 55, 123-138. doi: 10.2307/4697

De Kort, S. R., Eldermire, E. R. B., Cramer, E. R. A., and Vehrencamp, S. L. (2009). The deterrent effect of bird song in territory defense. Behav. Ecol. 20, 200-206. doi: 10.1093/beheco/arn135

Dowling, J. L., and Webster, M. S. (2013). The form and function of duets and choruses in red-backed fairy-wrens. Emu 113, 282-293. doi: 10.1071/MU12082

Elie, J. E., Mariette, M. M., Soula, H. A., Griffith, S. C., Mathevon, N., and Vignal, C. (2010). Vocal communication at the nest between mates in wild zebra finches: a private vocal duet? Anim. Behav. 80, 597-605. doi: 10.1016/j.anbehav.2010.06.003
Ficken, R. W., Ficken, M. S., and Hailman, J. P. (1974). Temporal pattern shifts to avoid acoustic interference in singing birds. Science 183, 762-763. doi: 10.1126/science. 183.4126 .762

Fortune, E. S., Rodriguez, C., Li, D., Ball, G. F., and Coleman, M. J. (2011). Neural mechanisms for the coordination of duet singing in wrens. Science 334, 666-670. doi: $10.1126 /$ science. 1209867

Garamszegi, L. Z., Pavlova, D. Z., Eens, M., and Moller, A. P. (2007). The evolution of song in female birds in Europe. Behav. Ecol. 18, 86-96. doi: 10.1093/beheco/arl047

Gill, S. A., Vonhof, M. J., Stutchbury, B. J. M., Morton, E. S., and Quinn, J. S. (2005). No evidence for acoustic mate-guarding in duetting buff-breasted wrens (Thryothorus leucotis). Behav. Ecol. Sociobiol. 57, 557-565. doi: 10.1007/s00265004-0893-3

Halkin, S. L. (1997). Nest-vicinity song exchanges may coordinate biparental care of northern cardinals. Anim. Behav. 54, 189-198. doi: 10.1006/anbe.1996.0415

Hall, M. L. (2004). A review of hypotheses for the functions of avian duetting. Behav. Ecol. Sociobiol. 55, 415-430. doi: 10.1007/s00265-003-0741-x

Hall, M. L. (2006). Convergent vocal strategies of males and females are consistent with a cooperative function of duetting in Australian magpie-larks. Behaviour 143, 425-449. doi: 10.1163/156853906776240623

Hall, M. L. (2009). A review of vocal duetting in birds. Adv. Study Behav. 40, 67-121. doi: 10.1016/S0065-3454(09)40003-2

Hall, M. L., Illes, A., and Vehrencamp, S. L. (2006). Overlapping signals in banded wrens: long-term effects of prior experience on males and females. Behav. Ecol. 17, 260-269. doi: 10.1093/beheco/arj022

Hall, M. L., and Magrath, R. D. (2000). Duetting and mate-guarding in Australian magpie-larks (Grallina cyanoleuca). Behav. Ecol. Sociobiol. 47, 180-187. doi: $10.1007 / \mathrm{s} 002650050009$

Hall, M. L., Molles, L. E., Illes, A. E., and Vehrencamp, S. L. (2009). Singing in the face of death: male banded wrens Thryophilus pleurostictus sing more to playback in their last breeding season. J. Avian Biol. 40, 217-224. doi: 10.1111/j.1600-048X.2009.04540.x

Hall, M. L., and Peters, A. (2008). Coordination between the sexes for territorial defence in a duetting fairy-wren. Anim. Behav. 76, 65-73. doi: 10.1016/j.anbehav.2008.01.010

Hoelzel, A. R. (1986). Song characteristics and response to playback of male and female robins Erithacus rubecula. Ibis 128, 115-127. doi: 10.1111/j.1474919X.1986.tb02098.x

Illes, A. E., Hall, M. L., and Vehrencamp, S. L. (2006). Vocal performance influences male receiver response in the banded wren. Proc. R. Soc. Lond. B Biol. Sci. 273, 1907-1912. doi: 10.1098/rspb.2006.3535

Illes, A. E., and Yunes-Jimenez, L. (2009). A female bird out-sings male conspecifics during simulated territorial intrusions. Proc. R. Soc. Lond. B 276, 981-986. doi: 10.1098/rspb.2008.1445

Kleindorfer, S., Evans, C., Mihailova, M., Colombelli-Negrel, D., Hoi, H., Griggio, M., et al. (2013). When subspecies matter: resident superb fairy-wrens (Malurus cyaneus) distinguish the sex and subspecies of intruding birds. Emu 113, 259-269. doi: 10.1071/MU12066

Kovach, K. A., Hall, M. L., Vehrencamp, S. L., and Mennill, D. J. (2014). Timing isn't everything: responses of tropical wrens to coordinated duets, uncoordinated duets and alternating solos. Anim. Behav. 95, 101-109. doi: 10.1016/j.anbehav.2014.06.012

Kroodsma, D. E. (1976). Reproductive development in a female songbird: differential stimulation by quality of male song. Science 192, 574-575. doi: 10.1126/science.192.4239.574

Langmore, N. E. (1998). Functions of duet and solo songs of female birds. Trends Ecol. Evol. 13, 136-140. doi: 10.1016/S0169-5347(97)01241-X

Langmore, N. E., and Davies, N. B. (1997). Female dunnocks use vocalizations to compete for males. Anim. Behav. 53, 881-890. doi: 10.1006/anbe.1996.0306

Langmore, N. E., Davies, N. B., Hatchwell, B. J., and Hartley, I. R. (1996). Female song attracts males in the alpine accentor Prunella collaris. Proc. R. Soc. B.Biol. Sci. 263, 141-146. doi: 10.1098/rspb.1996.0022

Levin, R. N. (1996). Song behaviour and reproductive strategies in a duetting wren, Thryothorus nigricapillus: I. Removal experiments. Anim. Behav. 52, 1093-1106. doi: 10.1006/anbe.1996.0257

Logue, D. M. (2005). Cooperative defence in duet singing birds. Cogn. Brain Behav. 9, 497-510. doi: 10.1006/anbe.1996.0258

Logue, D. M. (2006). The duet code of the female black-bellied wren. Condor 108, 326-335. doi: 10.1650/0010-5422(2006)108[326:TDCOTF]2.0.CO;2 
Logue, D. M. (2007a). Duetting in space: a radio-telemetry study of the black-bellied wren. Proc. R. Soc. B Biol. Sci. 274, 3005-3010. doi: 10.1098/rspb.2007.1005

Logue, D. M. (2007b). How do they duet? Sexually dimorphic behavioural mechanisms structure duet songs in the black-bellied wren. Anim. Behav. 73, 105-113. doi: 10.1016/j.anbehav.2006.05.011

Logue, D. M., Chalmers, C., and Gowland, A. H. (2008). The behavioural mechanisms underlying temporal coordination in black-bellied wren duets. Anim. Behav. 75, 1803-1808. doi: 10.1016/j.anbehav.2007.10.036

Logue, D. M., and Gammon, D. E. (2004). Duet song and sex roles during territory defence in a tropical bird, the black-bellied wren, Thryothorus fasciatoventris. Anim. Behav. 68, 721-731. doi: 10.1016/j.anbehav.2003.10.026

Mann, N. I., Dingess, K. A., Barker, F. K., Graves, G. R., and Slater, P. J. B. (2009). A comparative study of song form and duetting in neotropical Thryothorus wrens. Behavior 146, 1-43. doi: 10.1163/156853908X390913

Mann, N. I., Marshall-Ball, L., and Slater, P. J. B. (2003). The complex song duet of the plain wren. Condor 105, 672-682. doi: 10.1650/7208

Mariette, M. M., and Griffith, S. C. (2012). Nest visit synchrony is high and correlates with reproductive success in the wild Zebra finch Taeniopygia guttata. J. Avian Biol. 43, 131-140. doi: 10.1111/j.1600-048X.2012.05555.x

Marshall-Ball, L., Mann, N., and Slater, P. J. B. (2006). Multiple functions to duet singing: hidden conflicts and apparent cooperation. Anim. Behav. 71, 823-831. doi: 10.1016/j.anbehav.2005.05.021

Marshall-Ball, L., and Slater, P. J. B. (2008). Repertoire sharing by the individual and the pair: insights into duet function and development in the plain wren Thryothorus modestus. J. Avian Biol. 39, 293-299. doi: 10.1111/j.09088857.2008.04060.x

Maynard, D. F., Ward, K-A. A., Doucet, S. M., and Mennill, D.J. (2012). Calling in an acoustically competitive environment: duetting male long-tailed manakins avoid overlapping neighbours but not playback-simulated rivals. Anim. Behav. 84, 563-573. doi: 10.1016/j.anbehav.2012.06.008

Mays, H. L., Yao, C. T., and Yuan, H. W. (2006). Antiphonal duetting in Steere's liocichla (Liocichla steerii): male song individuality and correlation between habitat and duetting behavior. Ecol. Res. 21, 311-314. doi: 10.1007/s11284-0050115-0

McComb, K., Packer, C., and Pusey, A. (1994). Roaring and numerical assessment in contests between groups of female lions, Panthera leo. Anim. Behav. 47, 379-387. doi: 10.1006/anbe.1994.1052

McGregor, P. K., and Krebs, J. R. (1982). Song types in a population of great tits (Parus major) - their distribution, abundance and acquisition by individuals. Behaviour 79, 126-152. doi: 10.1163/156853982X00210

Mennill, D. J., and Vehrencamp, S. L. (2005). Sex differences in singing and duetting behavior of neotropical rufous-and-white wrens (Thryothorus rufalbus). Auk 122, 175-186. doi: 10.1642/0004-8038(2005)122 [0175:SDISAD]2.0.CO;2

Mennill, D. J., and Vehrencamp, S. L. (2008). Context-dependent functions of avian duets revealed by microphone-array recordings and multispeaker playback. Curr. Biol. 18, 1314-1319. doi: 10.1016/j.cub.2008.07.073

Molles, L. E. (1999). Use of Song-type Repertoires by Banded Wrens. PhD thesis, University of California.

Molles, L. E., and Vehrencamp, S. L. (1999). Repertoire size, repertoire overlap, and singing modes in the banded wren (Thryothorus pleurostictus). Auk 116, 677-689. doi: 10.2307/4089329

Molles, L. E., and Vehrencamp, S. L. (2001). Songbird cheaters pay a retaliation cost: evidence for auditory conventional signals. Proc. R. Soc. Lond. B Biol. Sci. 268, 2013-2019. doi: 10.1098/rspb.2001.1757

Mosser, A., and Packer, C. (2009). Group territoriality and the benefits of sociality in the African lion, Panthera leo. Anim. Behav. 78, 359-370. doi: 10.1016/j.anbehav.2009.04.024

Naguib, M. (1999). Effects of song overlapping and alternating on nocturnally singing nightingales. Anim. Behav. 58, 1061-1067. doi: 10.1006/anbe.1999.1223

Odom, K. J., Hall, M. L., Riebel, K., Omland, K. E., and Langmore, N. E. (2014). Female song is widespread and ancestral in songbirds. Nat. Commun. 5:3379. doi: $10.1038 /$ ncomms4379

Pavlova, D., Pinxten, R., and Eens, M. (2005). Female song in European starlings: sex differences, complexity, and composition. Condor 107, 559-569. doi: 10.1650/0010-5422(2005)107[0559:FSIESS]2.0.CO;2

Pavlova, D. Z., Pinxten, R., Darras, V. M., and Eens, M. (2007). Effects of nestboxes and males on female song activity in the European starling: an experimental study. Behaviour 144, 1255-1271. doi: 10.1163/156853907781890968
Pilowsky, J. A., and Rubenstein, D. R. (2013). Social context and the lack of sexual dimorphism in song in an avian cooperative breeder. Anim. Behav. 85, 709-714. doi: 10.1016/j.anbehav.2013.01.012

Price, J. J., Yunes-Jimenez, L., Osorio-Beristain, M., Omland, K. E., and Murphy, T. G. (2008). Sex-role reversal in song? Females sing more frequently than males in the streak-backed oriole. Condor 110, 387-392. doi: 10.1525/cond.2008.8430

R Core Team. (2014). R: A Language and Environment for Statistical Computing. Vienna: R Foundation for Statistical Computing. Available online at: http:// www.R-project.org/.

Riebel, K. (2003). The "mute" sex revisited: vocal production and perception learning in female songbirds. Adv. Study Behav. 33, 49-86. doi: 10.1016/S00653454(03)33002-5

Riebel, K., Hall, M. L., and Langmore, N. E. (2005). Female songbirds still struggling to be heard. Trends Ecol. Evol. (Amst.) 20, 419-420. doi: 10.1016/j.tree.2005.04.024

Rogers, A. C., Langmore, N. E., and Mulder, R. A. (2007). Function of pair duets in the eastern whipbird: cooperative defense or sexual conflict? Behav. Ecol. 18, 182-188. doi: 10.1093/beheco/arl070

Rogers, A. C., and Mulder, R. A. (2004). Breeding ecology and social behaviour of an antiphonal duetter, the eastern whipbird (Psophodes olivaceus). Aust. J. Zool. 52, 417-435. doi: 10.1071/ZO04001

Schwabl, H. (1992). Winter and breeding territorial behavior and levels of reproductive hormones of migratory European robins. Ornis Scand. 23, 271-276. doi: $10.2307 / 3676649$

Searcy, W. A., and Beecher, M. D. (2009). Song as an aggressive signal in songbirds. Anim. Behav. 78, 1281-1292. doi: 10.1016/j.anbehav.2009.08.011

Sethi, V. K., Bhatt, D., and Kumar, A. (2012). Structure and context of female song in a tropical bird, the pied bush chat. Curr. Sci. 103, 827-832.

Short, L. L., and Horne, J. F. M. (1982). Vocal and other behaviour of Kenyan black-collared barbets Lybius torquatus. Ibis 124, 27-43. doi: 10.1111/j.1474919X.1982.tb03738.x

Thorpe, W. H. (1963). Antiphonal singing in birds as evidence for avian auditory reaction time. Nature 197, 774-776. doi: 10.1038/197774a0

Tobias, J. A., Montgomerie, R., and Lyon, B. E. (2012). The evolution of female ornaments and weaponry: social selection, sexual selection and ecological competition. Philos. Trans. R. Soc. B Biol. Sci. 367, 2274-2293. doi: 10.1098/rstb.2011.0280

Trillo, P. A., and Vehrencamp, S. L. (2005). Song types and their structural features are associated with specific contexts in the banded wren. Anim. Behav. 70, 921-935. doi: 10.1016/j.anbehav.2005.02.004

Trivers, R. L. (1972). "Parental investment and sexual selection," in Sexual Selection and the Descent of Man, 1871-1971, ed B. Campbell (London: Heinemann), $136-179$.

Vehrencamp, S. L., Ellis, J. M., Cropp, B. F., and Koltz, J. M. (2014). Negotiation of territorial boundaries in a songbird. Behav. Ecol. 25, 1436-1450. doi: 10.1093/beheco/aru135

Vehrencamp, S. L., Hall, M. L., Bohman, E. R., Depeine, C. D., and Dalziell, A. H. (2007). Song matching, overlapping, and switching in the banded wren: the sender's perspective. Behav. Ecol. 18, 849-859. doi: 10.1093/beheco/arm054

Conflict of Interest Statement: The Reviewer David Michael Logue declares that, despite having co-authored a manuscript with author Michelle Hall in 2014, the review process was handled objectively and no conflict of interest exists. The authors declare that the research was conducted in the absence of any commercial or financial relationships that could be construed as a potential conflict of interest.

Received: 14 October 2014; accepted: 30 January 2015; published online: 17 February 2015.

Citation: Hall ML, Rittenbach MRD and Vehrencamp SL (2015) Female song and vocal interactions with males in a neotropical wren. Front. Ecol. Evol. 3:12. doi: 10.3389/fevo.2015.00012

This article was submitted to Behavioral and Evolutionary Ecology, a section of the journal Frontiers in Ecology and Evolution.

Copyright (C) 2015 Hall, Rittenbach and Vehrencamp. This is an open-access article distributed under the terms of the Creative Commons Attribution License (CC BY). The use, distribution or reproduction in other forums is permitted, provided the original author(s) or licensor are credited and that the original publication in this journal is cited, in accordance with accepted academic practice. No use, distribution or reproduction is permitted which does not comply with these terms. 